\title{
O regime regulatório e o mercado de planos de saúde no Brasil
}

\author{
The regulatory regime and the health insurance industry in Brazil
}

N ilson do Rosário Costa ${ }^{1}$

\footnotetext{
${ }^{1}$ Departamento deCiências Sociais, Escola Nacional de SaúdePública. Rua Leopoldo Bulhões 1480, Manguinhos. 21041-210 Rio deJaneiro RJ. nilson@ensp.fiocruz.br
}

Abstract This paper analyzes the regulatory regimefor health insuranceand prepayment schemes in Brazil. It describes the ideas that have influenced the creation of the Agência $\mathrm{Nacional}$ de SaúdeSuplementar-ANS (N ational Agency of Supplementary $\mathrm{H}$ ealth) in 2000, showing that the independent agency model was a direct result of the privatization process and of the induction of new competition mechanisms in a natural state monopoly. The paper concludes that the prepayment firms in Brazil are facing a new institutional environment as refers to their market entry or exit conditions.

Key words Regulatory regime, Independent agency, Government failures, Health insurance industry, National heath system
Resumo 0 artigo analisa o regime de regulação do mercado deplanos privados deassistência à saúde - Brasil. I dentifica a origem da Agência Nacional deSaúde Suplementar (ANS) e descreveosinstrumentos de regulação que detém para intervir na indústria de planose seguro saúdebrasileira. Estabelece a associação do modelo organizacional da agência independente aplicado à ANS aos processos de privatização e desenvolvimento da regulação dos servi ços públicos de monopólio natural no Brasil. 0 artigo demonstra que o regime de regulação afeta fortemente as condições de entrada e saída do mercado de planos de saúde.

Palavras-chave Regime de regulação, A gência reguladora, Falhas de governo, Seguro saúde, Sistema de saúde 
Introdução

Neste artigo, o regime regulatório é definido como o modo que as instituições estatais (organizações e agentes públicos) atuam sobre um setor da economia. A reforma regulatória é a descrição das mudanças na indústria de serviços de utilidade pública nas economias industriais: de um monopólio de propriedade estatal para empresas com novos proprietários, novas instituições regulatórias, novas estruturas industriais, novos competidores e novos métodos de controlar seu comportamento.

Essas reformas regulatórias não resultaram das preferências do mercado ou de grupos de interesse, mas derivam, em suas características essenciais, da forma como instituições estatais, localizadas no Executivo, mediaram suas relações com os interesses organizados do merca$\mathrm{do}^{1,2}$. A reforma regulatória objetiva ampliar 0 padrão de eficiência macroeconômica pela indução à concorrência em áreas de monopólio natural e criar novos mecanismos para a implementação de políticas públicas no contexto pós-re forma patrimonial do Estado.

A reforma regulatória afeta a capacidade dos atores estatais desempenharem suas funções. A regulação pela propriedade pública foi durante décadas o principal meio de regulação na área de infra-estrutura: gás, eletricidade, indústria de água, ferrovias, telégrafos e serviços telefônicos. Essas indústrias exibiam as características de monopólios naturais, porque seria mais eficiente produzir por meio de uma única empresa do que por várias, em decorrência da economia de escala. 0 apoio público a essas empresas deu ao Estado o poder deimpor uma estrutura planejada de economia e de proteger o interesse público contra a intervenção dos interesses privados.

A estatização teria falhado não só com respeito aos objetivos econômicos de regulação e controle, mas também quanto aos objetivos sociais de proteção ao consumidor e de responsabilização pública - pela negação sistemática de informação sobre formação das tarifas e apadrinhamento na contratação de pessoal ${ }^{1}$. Neste cenário, tornou-seaceitável a tese de queo interesse público pode ser preservado e desenvolvido frenteàs atividades de mercado por meio decontroles legais eincentivos organizacionais manejados externamente por uma agência reguladora ${ }^{3}$.

As agências especializadas foram estabelecidas por estatuto como autoridade independente e receberam a permissão para operar fora da linha de controle hierárquico e de supervisão do governo central. Esse modo de regulação representaria a nova fronteira da política e administração públicas nas economias industrializadas².

A maior complexidade da política pública reduz a efetividade da técnica de governo da administração direta (control-and-command techniques). As novas tar efas de governo são dificultadas não só porque lidam com assuntos tecnologicamente complexos, mas porque tentam modificar as expectativas e as condutas. Daí, a busca por credibilidade tende a substituir o poder coercitivo como recurso essencial da decisão políti$\mathrm{ca}^{3}$. Os governos têm delegado poderes para uma organização independente, como um meio delegitimação das estratégias regulatórias que não teriam credibilidade de outro modo. São notáveis o poder de arbítrio e a independência organizacional concedidos aos novos reguladores nas economias industriais avançadas. Suas atribuições foram para além do monitoramento e autorização para funcionamento, intervindo no sistema de preços equalidade de serviço, nas condições de financiamento das atividades concedidas e na própria estrutura dos mercados setoriais.

Vogel chama atenção que o regime regulatório pode sobreviver às mudanças de governo quando assume um formato organizacional na estrutura da burocracia pública ${ }^{1}$.

A dimensão organizacional de um regimeregulatório tende a expressar um conjunto de preferências de atores estatais: na estruturação de grupos deinteresses, na definição de capacidades de estado e das condições de interação entre 0 Estado e os interesses empresariais. As condições organizacionais da regulação influenciam tanto o formato do aparato do Estado como da atividade econômica ${ }^{1}$.

Se analisadas da perspectiva da incidência dos custos e benefícios gerados pela decisão pública, como demonstra Wilson ${ }^{4}$, as políticas regulatórias apresentam uma clara diferença em relação às demais tipologias da interven ção do governo sobre as atividades de empresas e cidadãos. As políticas regulatórias podem buscar soluções de soma positiva, ou seja, podem ser implementadas por agentes públicos na expectativa de que todos os setores afetados pela intervenção do governo sejam ganhadores, pelo bem público gerado.

Ainda assim, o risco da captura das agências independentes pelo setor industrial regulado não deixa de ser uma grande preocupação dos especialistas e entidades de consumidores. Scott ${ }^{5}$ assinala, nesta perspectiva, que a teoria econômica da regulação é cética quanto à possível geração de benefício público pela política regulatória. A 
teoria econômica da regulação argumenta que o comportamento dos reguladores deve ser explicado tomando com referência o comportamento padrão dos agentes econômicos. Estes agentes se comportam orientados pela obtenção de"rendas". A regulação governamental é orientada por aqueles que oferecerem maiores retornos aos re guladores. N estas condições, a regulação será sempre favorável às maiores empresas por que estas detêm melhores condições de geração de rendas. A promoção do interesse público éaúltima das motivações do regime regulatório.

A percepção de que a regulação é uma arena de políticas que pode gerar benefícios públicos ou mesmo vantagens para as burocracias e políticas que a implementa explica a variedade de demanda por sua expansão nos Estados nacionais ${ }^{4}$. 0 crescimento das atividades regulatórias tem estimulado a intervenção crescente dos governos em nome de consumidores, na proteção decontratos ena provisão debens públicos. Com isso, a política pública regulatória torna crível a tese de que o mercado por si só não gera a alocação ótima e virtuosa de recursos em qualquer circunstância ${ }^{3}$.

\section{O aprendizado institucional da regulação}

A principal fonte de aprendizado institucional sobre a regulação das fal has de mercado vem do regime regulatório para as empresas de serviços de utilidade pública. A reforma regulatória nesse segmento industrial buscou estimular a competição e diminuir a regulação formal e burocrática. O principal mecanismo organizacional desse processo de inovação foi a criação da agência reguladora delegada e autônoma ${ }^{3,5}$. Além de serem responsáveis pelos processos detran sferência da propriedade - técnicas de venda, preços das ações, receitas obtidas, efeitossobrea divisão depropriedade, etc., as agências regulatórias respondem pelo desempenho das empresas privatizadas.

Nos mercados competitivos, evidência demonstra que a al ocação privada tende a ser mais eficiente do que a alocação pública; porém, as respostas são menos conclusivas para as empresas de serviços de utilidade pública mesmo que privadas. $\mathrm{N}$ as atividades com alto poder de mercado ou risco de fal has de mercado, independentemente da natureza da propriedade ou da mudança de propriedade, osincentivos para a eficiência dependem criticamente do regime decompe tição e regulação com o qual o setor opera.

Armstrong et al. ${ }^{6}$ chamam a atenção para 0 fato de que o regime regulatório por agência delegada é crucial para determinar como a nova forma de propriedade funcionará, se a meta de eficiência da privatização será al cançada e como será o desempenho de o setor econômico como um todo, sob propriedade pública ou privada. Em resumo, incentivos para a eficiência dependem das regras de competição e da regulação, e não apenas do regime de propriedade. A propriedade privada per si não égarantia para a eficiência e qualidade. As empresas privadas numa posição de dominância de mercado não hesitam em ampliar suas rendas.

Em linhas gerais, um mercado livrepodesignificar que a regulação privada organizada por cartéis impediráa competição. Por outro lado, a regulação estatal indiscriminada pode ser facilmente contornada por real inhamento no posicionamento estratégico das empresas no seu mercado relevante. Evidências sugerem que uma boa política regulatória combina necessariamenteaspectos da regulação estatal com a auto-regulação?.

A estratégia das agências regulatórias deve considerar a especificidade das empresas e dos ramos industriais e de serviços e promover um escalonamento do grau de intervenção estatal direta através de punições. Uma estratégia baseada principalmentena punição enfraqueceráa iniciativa inovadora de agentes empresariais socialmente responsáveis.

Para M ajone ${ }^{3}$, a questão crítica é saber se as categorias normativas para a construção do bemestar econômico conseguem orientar efetivamente a atuação adequada das agências de governo em nome do interesse público. A evidência de avaliação de casos concretos de atuação de agências reguladoras, buscando a correção de falhas de mercado, aponta dois riscos: a captura pelos interesses dos agentes públicos que implementam tais políticas e a desfiguração desta missão institucional pela influência do setor econômico regulado.

Os riscos potenciais desse processo, comparados aos mecanismos de controle direto, são resumidos no Quadro 1.

A tipologia das fal has governamentais na regulação, resumidas no Quadro 1, resgata al guns dos pontos identificados pela escola teórica da econômica da regulação. I dentifica os efeitos perversos não antecipados da regulação, a maioria diretamente associada à "captura" dos reguladores pelos regulados e à baixa responsabilização das agências independentes.

Esta agenda é de grande relevância para 0 debate sobre o desenvolvimento do novo regime 
de regulação para os diversos setores indústrias e de serviços no Brasil. 0 modelo de regulação por agência independente adotado aqui, diante das mudanças dos mecanismos de governança da propriedade pública, mirou-se explicitamente nas soluções internacionais para o setor de telecomunicação.

0 desenho dos novos entes reguladores obedeceu a um conjunto de orientações que foram assim resumidas por Nunes': autonomia decisória; ampla divulgação de decisões e procedimentos; celeridade nas relações com os consumidores e agentes econômicos; inclusão dos interessados em audiências públicas e limitação da ação estatal na provisão de serviços públicos.

Um aspecto relevante está na adoção do modelo autárquico especial: a autonomia daí decorrenterepercuteno grau deinsulamento dos diretores nomeados. Embora a duração dos mandatos varie, assim com a possibilidade de recondução, existem cláusulas deestabilidadenas funções, assim como regulamentos voltados a isolar as relações entre os diretores e os agentes econômicos e atores políticos no setor. Este grau de insulamento tem se mostrado objeto de grande disputa edissenso político, em razão das funções bastante amplas desempenhadas pelas agências criadas no Brasil ${ }^{8}$.
Regimeregulatório eas empresas de planos privados deassistência à saúde no Brasil

0 mercado de planos privados de assistência à saúde no Brasil desenvolveu-se em um contexto institucional de baixa regulação, atéfins da década de 1990, a despeito dos incentivos denatureza fiscal e da ausência de barreiras de entrada e saída para novas empresas.

Essas extraordinárias condições institucionais para a atividade econômica favoreceram a ampliação da clientela e a abertura de empresas de diferentes portes, que fazem a intermediação do acesso à atenção à saúde em todas as cidades de médio e grande porte do Brasil. 0 segmento de planos de assistência à saúde compreende um universo diferenciado de modalidades organizacionais: empresas de medicina de grupo, empresas de autogestão (públicas e privada), seguradoras, cooperativas médicas e odontológicas?.

A Constituição do marco regulatório pela Lei no 9.656/98 e a criação da Agência Nacional de SaúdeSuplementar (ANS) em 2000 modificaram significativamenteesse cenário, pela definição de novas regras de proteção aos consumidores e de entrada, permanência e saída das empresas no mercado. No contexto anterior à regulação, como já assinal ado, os estudos sobre o setor iden-

Quadro 1. As falhas dos dois tipos de regulação de serviços públicos.

\begin{tabular}{|l|l|}
\hline Regulação por delegações (agência) & Regulação pela verticalização por empresas estatais \\
\hline Captura dos reguladores pelas empresas reguladas & $\begin{array}{l}\text { Captura das empresas públicas por políticos e } \\
\text { sindicatos }\end{array}$ \\
\hline $\begin{array}{l}\text { Inflação tarifária (ou excessiva capitalização das } \\
\text { empresas reguladas) }\end{array}$ & Excesso de pessoal \\
\hline $\begin{array}{l}\text { A regulação leva à queda da concorrência na } \\
\text { indústria em médio prazo }\end{array}$ & M onopólio público \\
\hline $\begin{array}{l}\text { Objetivos difusos para a definição do que seja } \\
\text { interesse público (considerando que a agência } \\
\text { autônoma regula em nome do interesse público) }\end{array}$ & $\begin{array}{l}\text { Orientação dos gestores públicos por metas } \\
\text { ambíguas e inconsistentes }\end{array}$ \\
\hline $\begin{array}{l}\text { Falhas na coordenação entre diferentes funções de } \\
\text { regulação }\end{array}$ & $\begin{array}{l}\text { Pobreza na coordenação entre diferentes } \\
\text { empresas públicas }\end{array}$ \\
\hline $\begin{array}{l}\text { Insuficiente responsabilização política das agências } \\
\text { regulatórias independentes }\end{array}$ & $\begin{array}{l}\text { Nenhum controle efetivo das empresas públicas } \\
\text { pelo Congresso, tribunais ou ministério gestor. }\end{array}$ \\
\hline
\end{tabular}

Fonte: Adaptado de M ajone?. 
tificavam problemas de exclusões e variações no escopo e natureza da cobertura, em quase todos os planos privados, permitindo que opções desfavoráveis fossem oferecidas ao consumidor ${ }^{10}$.

$\mathrm{Na}$ ausência de um marco regulatório apropriado no Brasil, o segmento do mercado deplanos de assistência à saúde operou por mecanismos bastante frágeis quanto ao nível de informação ao consumidor; portanto, como uma com forte orientação risk-avoidance em vários itens relevantes de contrato.

Esta estratégia afetou os ben eficiários de planosindividuais quecontraíssem enfermidades de alto custo ou de tratamento de longa duração, como o caso das doenças mentais, que não eram cobertas pela maioria dos contratos e ficaram sob a gestão e assistência do Sistema ú nico de Saúde. Esse fato motivou uma agenda importante para a discussão das relações público e privado no Brasil no âmbito do setor saúde, abrindo espaço para a regulação na perspectiva inicial do direito do consumidor e do respeito a contratos e, posteriormente, na construção de regime regulatório que interfere fortemente sobre a atividade empresarial do setor.

A intervenção normativa da ANS tem sido, assim, orientada para garantir o desenvolvimento de novos contratos que contemplem a eqüidade nas condições de cobertura, a extinção dos limites de internação, a proibição de aumento por faixa etária após 60 anos com dez anos de contribuição ea qualidade mínima nos padrões deatenção. 0 desenvolvimento da política governamental no mercado de seguro de saúde apresenta as características esperadas para as funções regulatórias ${ }^{3,4,12}$, mas não explicita uma proposta clara para a estrutura de mercado, ao contrário da regulação na área de infra-estrutura.

A criação da AN S deu início a um regime re gulatório abrangente exercido pelo Executivo Federal, que afeta profundamente todas as modalidades de atividade no mercado de planos de assistência à saúde, como já demonstrado.

0 regime regulatório sob a égide da ANS tem gerado normas, padrões e sanções a empresas de planos privados de saúde que podem ser responsabilizados pela qualidade dos contratos, pela seleção do risco e pela adequação da administração financeira. A regulação da qualidadeda prestação da atenção à saúde dos prestadores ainda não recebeu uma definição abrangente, ainda que esteja latente na cultura técnica da ANS.

A Agência Nacional de Saúde Suplementar (ANS) foi criada através da medida provisória no 2.012-2, de 30 de dezembro de 1999. A matriz de implementação da ANS é modelada pelas experiências dos serviços deutilidade pública, variando a interface com organismos soci etários e 0 grau de mediação dos grupos de interesse ${ }^{8}$.

A criação da ANS foi o princípio do estabelecimento de jurisprudência regulatória sobre a medicina de pré-pagamento, das cooperativas médicas e dos planos deempresas. Antes, o seguro-saúde estava sob a jurisdição da SU SEP (Superinten dência deSeguros Privados). A pesar disso, em todos os segmentos, persistiu a exclusão de segurados de alto risco e de opções de tratamento ou diagnósticos onerosos.

0 desenvolvimento da política governamental no mercado de saúde suplementar no Brasil apresenta as características esperadas para as funções regulatórias. Cabe a ANS, entre outras competências normativas:

. Estabelecer critérios para a concessão, manutenção e cancelamento da autorização de funcionamento das empresas e de registro de produtos;

. Estabelecer critérios de monitoramento e controle do acesso, manutenção e qualidade dos serviços de assistência à saúde das empresas, sejam eles próprios, credenciados ou referenciados;

- Avaliar a capacidadetécnico-operacional das empresas;

- Definir o rol de procedimentos e eventos de saúde que constituem a referência básica para as coberturas assistenciais, inclusive quanto à cobertura parcial temporária, nas hipóteses de lesão ou doença preexistente;

- Monitorar a evolução dos preços dos planos, dos seus prestadores de serviços e respectivos componentes e insumos, bem como autorizar reajustes e revisões das contraprestações pecuniárias, ouvido o M inistério da Saúde;

. Estabelecer normas de ressarcimento ao SUS;

. Estabelecer critérios de garantias de manutenção do equilíbrio econômico-financeiro das empresas, assim como de normas e padrões para 0 envio de informações;

- Autorizar os processos de cisão, fusão, incorporação ou transferência do controle societário das empresas, ouvidos os órgãos do sistema de defesa da concorrência;

- Estabelecer critérios gerais para o exercício de cargos diretivos das empresas;

- Instituir o regime de direção fiscal ou técnica nas empresas, proceder à liquidação extrajudicial da operadora e requerer sua falência ou insolvênciacivil;

- Determinar a alienação da carteira;

- Requisitar o fornecimento de informações 
às empresas, bem como à rede prestadora de serviço a el a credenciada ou referenciada;

- Celebrar com as empresas termo de compromisso de ajuste de conduta e fiscalizar ser cumprimento ${ }^{12}$.

Com as novas regras criadas a partir da Lei no $9.656 / 98$, as empresas que comercializam os planos individuais são obrigadas a cobrir nos novos contratos, por exemplo, tratamentos de câncer, doenças congênitas, transtornos psiquiátricos, AIDS, transplantes de rim e estão impedidas de negar assistência a portadores de doenças pré-existentes.

Essas regras valem apenas para os contratos de pessoa física (contratos individuais e familiares). Os contratos de pessoa jurídica (coletivos e empresariais) são realizados por negociação direta dos contratantes com as empresas, independentemente do contrato ter sido assinado antes ou depois da Lei no 9.656/98.

A despeito do ainda baixo impacto do poder regulador e da ausência da ANS sobre os contratos coletivos, o desafio normativo para a ANS refere-se, sobretudo, à clara avaliação dos efeitos gerados pelo regime regulatório sobre a estrutura das empresas ao definir regras importantes para sel eção de risco dos contratos individuais e para as firmas permanecerem e entrarem no mercado.

Os estudos sobre as relações entre regime re gulatório em mercados setoriais sugerem cautela em relação à capacidade de adaptação das dife rentes empresas às exigências formais da regulação. As restrições institucionais alteram o padrão de concorrência potencial pela indução indireta ou direta de mudanças nos custos operacionais das empresas 3 .

0 regimederegulação desenvolvido pelaANS:

- afeta a economia de escala e escopo das empresas na indústria pelo efeito seletivo das fortes barreiras institucionaisà permanência, entrada e saída;

. restringe a sobrevivência das empresas mais débeis quando aumenta as demandas sobre a qualidade da firma ea diferenciação de produto;

- aumenta os custos de transação pelo crescimento de despesas operacionais para manter a posição no mercado.

0 tema das barrei ras de entrada, permanência e saída é crucial nesse aspecto para compreender 0 efeito do novo regime regulatório sobre a estrutura do mercado. Os agentes estatais, ao produzirem regimes de regulação, alteram condições estruturais de entrada para novas empre sas. A ação da Agência N acional de Saúde Suple mentar (AN S), no caso específico do mercado de saúde suplementar, expressa uma enorme capacidade de restringir a entrada, a permanência ea saída de novas empresas ${ }^{13}$. Esta evidência trará conseqüências previsíveis para a estrutura do mercado, como a concentração pela saída das empresas menos eficientes ou de menor escala.

Lembra Araújo ${ }^{13}$ que a exigência, por exemplo, de capital inicial necessário para a viabilidade econômico-financeira de uma operadora determina fundamentalmente a forma de operação das empresas no mercado.

As barreiras à entrada derivadas de requerimentos de capital serão mais elevadas quanto maior a extensão e a qualidade da rede própria. A região de atuação também determina a necessidadedecapital para iniciar as operações. Quanto maior a abrangência geográfica, maior os requerimentos de capital.

Cabe perguntar em que medida a exigência do investimento inicial tornará mais difícil a entrada de uma nova empresa na indústria. Elevados requerimentos iniciais de capital são também geradores de barreiras à saída, pois esses investimentos são condicionados por ser custos irrecuperáveis (sunk costs) que irão ter importantes implicações sobre o comportamento estratégico das empresas ${ }^{14}$.

Como descreve Araújo ${ }^{13}$, para que as empresas entrantes se constituam como empresas, devem atender a algumas exigências do órgão regulador. Em primeiro lugar, devem possuir registro provisório defuncionamento junto à ANS, atendendo a requisitos dispostos na RDC $n^{\circ} 05$, de 18 de fevereiro de 2000, documento deconstituição da empresa e alterações posteriores, devendo ser devidamente registradas em Junta Comercial ou cartório, documento deinscrição dos controladores, administradores e membros do consel ho fiscal, consultivo, deliberativo, administrativo ou assemelhado no cadastro de pessoa física - CPF.

A ANS, na resolução normativa $n-11$, de 22 de julho de 2002, instituiu normas para o exercício de administrador das empresas. Os eleitos ou nomeados para os cargos de diretor, curador ou membros do conselho de administração ou deliberativo deverão ter experiência comprovada na área que forem atuar. Além dos requisitos de capacitação técnico-profissional, é exigido de o profissional ter reputação ilibada. Não pode ter nenhum impedimento legal, condenação por crime de prevaricação, acusação de corrupção ativa ou passiva, de concussão, de peculato, contra a economia popular ou ter participado de 
empresas que estejam em direção fiscal ou em liquidação extrajudicial.

Além das normas estabelecidas na RDC no 5 e RN № 11, as empresas devem atender aos requisitos constantes na RDC $n^{\circ} 77$, de 17 de julho de 2001, que dispõe sobre os critérios de constituição de garantias financeiras a serem observados pelas empresas.

A raújo ${ }^{13}$ assinala ainda quea RDC $n 077$ estabeleceu critérios para operação a serem observados pelas empresas. Segundo esta resolução, as empresas devem observar a regra do capital mínimo ou provisão para a operação, provisão de risco, índice de giro de operações e margem de solvência. As empresas com fins lucrativos observam capital mínimo e as empresas sem fins lucrativos observam provisão para operação ${ }^{13}$.

A ANS introduziu outros mecanismos de controle na área econômico-financeira e contábil que produzem evidências para acompanhar o comportamento do setor. O plano de contas foi criado pela RDC no 38, de 27 de outubro de 2000 , atendendo a uma necessidade de padronização do mercado. 0 plano de contas éo principal instrumento de controle operacional das empresas. Ele propicia uma coleta de dados para quea ANS analise 0 desempenho das empresas, permitindo também acompanhar o desempenho das empresas ao longo de sua existência; a comparação de desempenho deuma operadora com outras congêneres do mesmo e de diferentes portes. 0 plano de contas viabiliza o fornecimento, por parte das empresas, de informações ger enciais e cadastrais, mediante ao preenchimento do Documento de Informações Periódicas das Empresas- DIOPS e, também, facilita a fiscalização "in loco"13. bilita:

A adoção do plano de contas padrão possi-

- a análise de desempenho de uma mesma operadora ao longo de sua existência;

- a comparação de desempenho das empre sas com outras congêneres, do mesmo porte e igual forma jurídica e com outras de diferentes portes e outras formas jurídicas;

- a análise de custos de atendimento médicohospitalar-ambulatorial e odontológico.

Também cumprindo a disposição legal contida no art. 22 da Lei no 9.656 de 1998, foi exigida a publicação das demonstrações contábeis, acompanhadas do parecer dos auditores. Esta publicação foi exigida por operadora de grande, mé dio epequeno porte. Adotou-se como critério de porte das empresas de plano e seguro de saúde o número de beneficiários, sendo o primeiro corte de 1 a 20.000 por considerar ser este o número limite para uma diversificação mínima da carteira. 0 segundo corte, de 20.000 a 100.000 e o terceiro corte, acima de 100.000 beneficiários. Sendo que somente as empresas de plano e seguro de saúde com cartei ra acima de 20.000 ben eficiários tiveram que publicar seus demonstrativos contábeis.

0 mercado, atéa edição da RDC № 77, de 17 de julho de 2001, operava sem nenhuma regulamentação de garantias financeiras, ocasionando instabilidade no mercado, tanto para empresários quanto para consumidores.

Conforme a RDC $n^{\circ} 05$, de 18 de fevereiro de 2000, parafins decancelamento do registro provisório de funcionamento, isto é, para sair do mercado de saúde suplementar, o representante legal da operadora deverá apresentar à ANS solicitação de cancelamento dos planos registrados, bem como declaração de que não possui nenhum beneficiário e dívida com prestadores de serviços. A operadora deverá arcar, no mínimo, com o custo da transferência da sua carteira de beneficiários.

A Lei no 9.961 de 2000 estabelecea competência da ANS para fixar as normas para constituição, organização, funcionamento e fiscalização das empresas de plano e seguro de saúde cujos produtos sejam objetos de regulação.

Além da atribuição dos direitos de ingresso, acompanhamento das empresas e seus produtos e preços, tal competência inclui o poder de exclusão de empresas do mercado. A saída de uma operadora do mercado poderá ocorrer de duas formas: saída compulsória ou voluntária.

A saída compulsória poderá ser mediante a determinação da sua liquidação extrajudicial, quando houver risco no atendimento aos destinatários de tais atividades reguladas, constante no art. 4으, inciso XLI, alínea "d", da Lei no 9.961, de $2000^{13}$.

Assim, no exercício da regulação, envolvendo a normatização, controle e fiscalização das atividades que garantam a assistência suplementar à saúde, subordinam-se à ANS todas as pessoas jurídicas de direito privado que operam planos de assistência à saúde, nos termos do art. 10 da Lei $n$ ㅇ 9.656, de 3 dejunho de $1998^{13}$.

Pelo art. 23, da Lei no 9.656 de 1998, as empresas não podem requerer concordata e nem falência ou insolvência civil eficam submetidas ao regime deliquidação extrajudicial quando buscam a saída do mercado. De maneira diversa do que ocorre em outros segmentos regulados, mas à semel hança das instituições financeiras, o regime regulatório define que as empresas administram uma poupança privada, captada no mercado ${ }^{13}$. 
Assim, como atividade regulatória peculiar, além deinstaurar aliquidação extrajudicial, compete à ANS autorizar o respectivo liquidante a requerer a falência ou insolvência civil das empresas nas situações em que 0 ativo da massa liquidada não for suficiente para pagamento de pelo menos metade dos créditos pendentes, ou quando 0 ativo realizável da massa liquidada não for suficiente, sequer, para o pagamento das despesas administrativas eoperacionais inerentes ao regular processamento da liquidação extrajudicial, ou, ainda, nas hipóteses de fundados indícios de condutas previstas nos artigos 186 a 189 do Decreto-Lei no 7.661 , de 21 dejunho de 1945, conforme reza 0 art. 23 da Lei $n=9.656$ de $1998^{13}$.

É importante destacar que a ANS não é a liquidante, mas, meramente, quem determina a liquidação em decorrência de sua atividade reguladora. Cabe à ANS nomear o liquidante, com amplos poderes de administração e liquidação, sobretudo no que serefere à verificação e classificação dos créditos devidos, podendo propor ações e representar a massa em juízo ou fora dele ${ }^{13}$.

A liquidação extrajudicial ocorrerá quando houver indícios de problemas econômico-financeirosirrecuperáveis. A operadora deverá primeiramente passar por um plano de recuperação, contendo prazo e metas definidas, indicações precisas sobre os procedimentos a serem adotados pela operadora para sua recuperação ou direção fiscal e/ou direção técnica ${ }^{12}$.

O regime de direção fiscal ou de direção técnica éum mecanismo de regulação quefunciona como alternativa de correção das atividades econômico-financeiras das empresas.. Assim, se a operadora de planos de saúde estiver com dificuldades econômico-financeiras, ao invés de ser retirada do mercado, pode corrigir as fal has em que incidiu e regularizar seu funcionamento ${ }^{13}$.

Os regimes de direção fiscal e de direção técnica constituem alternativas à liquidação das empresas, que ficam assim mantidas no exercício de suas atividades, mas sob uma espécie de intervenção, semelhante à que ocorre nas instituições financeiras, que não ficam impedidas de prosseguir nas suas atividades. No caso da ANS, os regimes de direção fiscal e de direção técnica encontram-sefundados no art. 24 da Lei no 9.656 de 1998, posteriormente disciplinados pela RDC no 40 , de 12 de dezembro de $2000^{13}$.

A saída voluntária das empresas poderá ser por meio do pedido de cancelamento do registro, transferência de controle (acionário/societário) ou transferência da carteira.

É importante destacar que, na análise atual do mercado, as condições de entrada e saída das empresas são de fundamental importância na avaliação do seu grau de concorrência. Quanto mais elevadas forem as barreiras à entrada em um mercado, menor éa pressão competitiva exercida pelos entrantes potenciais sobre as empresas já estabelecidas.

A inexistência de baixas barreiras à entrada inibe comportamentos não competitivos das empresas, tais como o conluio e a cartelização, com o objetivo de fixar preços acima dos custos marginais (preços monopolísticos). A alocação dos recursos e o bem-estar social são indiretamente influenciados pelo nível das barreiras à entrada no mercado. Barreiras el evadas reduzem a competição que, por sua vez, determina o nível de preços e a eficiência alocativa do mercado.

Considera-seque existebarreira de entrada de uma nova empresa em uma indústria quando se exigea mobilização deelevada soma decapital para fazer face ao investimento inicial - as barreiras de capital. As barreiras de capital seria um reflexo direto da dificuldade em financiar os grandes volumes de capital requeridos quando o investimento inicial é muito elevado, não tendo qualquer relação com os impactos sobre os preços ou lucratividade provocados pelo momento da oferta total da indústria em conseqüência da entradaa-17.

Por outro lado, a ausência de barreiras à entrada em um mercado implica a existência deforte concorrência potencial, o que ésuficiente para impedir o surgimento e exercício de poder de mercado por parte das empresas. Uma avaliação detalhada do grau decompetição deum determinado mercado perpassa, naturalmente, por uma análise das barreiras à entrada, já que elevadas barreirasinibem a competição, implicando resultados tão mais distantes dos resultados competitivos quanto maiores forem estas barreiras.

Uma condição de entrada em uma indústria para possíveis novos produtores é avaliada pelas vantagens que as firmas estabelecidas possuem sobre os competidores potenciais. Essas vantagens se refletem na capacidade de elevar, persistentemente, os preços acima do nível competitivo, sem com isso atrair novas firmas para a indústria em questão.

As barreiras à entrada derivadas da diferenciação de produto decorrem da presença de elementosquefazem com que os consumidores considerem mais vantajoso adquirir um produto de empresas já existentes ao invés de similares oferecidos por novos concorrentes. Em mercados onde os produtos são muito diferenciados, os gastos em publicidade e propaganda inibem, de certa forma, a entrada de novos competidores. A fixação da marca para os consumidores exige el eva- 
dos investimentos em publicidade, até que os re sultados apareçam sob a forma de vendas.

As barreiras à entrada decorrentes da presença devantagensabsolutas de custo ocorrem quando as empresas estabelecidas têm acesso exclusivo a determinados ativos ou recursos, o que faz com que seus custos de produção sejam inferiores aos custos das novas empresas. Tais vantagens podem surgir da capacitação de recursos humanos qualificados, de tecnologias disponíveis apenas para as firmas já estabelecidas, do controle de suprimento de matérias- primas através da integração vertical, da compra de matérias-primas mais baratas e do menor custo de capitalização.

Um terceiro tipo de barreira de entrada são as economias de escala, ou seja, as reduções dos custos médios resultantes do aumento do nível de produção e da maior especialização.

Portanto, existem setores em que a escala mínima eficiente é el evada, restringindo a entrada de empresários de menor porte. Em mercados com grandes economias de escala frente ao tamanho do mercado, a tendência éa concentração da oferta.

Requerimentos el evados de capital para o início de operação também são fontes de barreiras à entrada. Um entrante potencial que não possua uma base de negócios significativa terá uma maior dificuldade em negociar empréstimosjunto ao mercado de capitais ${ }^{17 .}$

Já as barreiras à saída decorrem da existência de custos que as empresas necessitam incorrer para encerrar a produção. Esses custos podem ser desembolsos efetivos como, por exemplo, os custos de rescisão dos contratos em vigor, ou custos de oportunidade referentes a investimentos realizados e ainda não totalmente amortizados e que não tenham valor de revenda; os custos irrecuperáveis (sunk costs) ${ }^{14}$.

0 desenvolvimento do regime regulatório modifica substancialmente as condições de concorrência do mercado pela criação de novas condições de entrada, permanência e saída.

A questão central para o futuro do setor é saber o quanto a regulação das empresas, por força das novas exigências para saída, permanência e entrada na indústria, levará a concentração do mercado, fortalecendo a posição das empresas líderes. 0 futuro do setor dependerá de variáveis microeconômicas, como, por exemplo, a qualidade das carteiras das empresas em posição de saída da indústria.

Uma outra questão relevante éo desenvolvimento de capacidade institucional para avaliar os efeitos do processo de concentração sobre 0 bem-estar dos consumidores. A saída das pe- quenas empresas resultará na concentração do mercado. A tese aqui implícita é que, nas condições atuais de regulação, o mercado de planos de saúde tenderá a uma significativa concentração.

Um outro ponto importante diz respeito aos novos contratos para pessoa física, que oferecem coberturas abrangentes, novos direitos à população idosa (acima de 60 anos) e aos portadores de doenças préexistentes. Os novos contratos subordinam o reajuste de preço dos planos individuais efamiliares à autorização da ANS. As empresas buscarão impor o poder de mercado criando barreiras econômicas, pela elevação dos preços dos contratos individuais.

\section{Conclusão}

0 regime regulatório de mercados competitivos ou cartelizados (como a indústria demedicamentos) registra a dificuldade de desenvolvimento de capacidade institucional para projetar, implantar emanter um controle efetivo de qualidade de serviços e produtos ${ }^{10}$.

Um primeiro desafio normativo para a ANS refere-se à clara avaliação do impacto de suas funções normativas sobre a estrutura do mercado. Nos setores industriais, as agências foram desenvolvidas nos marcos da reforma do Estado e na formação e diversificação de mercados. A ANS, ao contrário, surge em função das falhas observadas entre as empresas e os consumidores. Suas funções se orientam à correção dos desequilíbrios nas relações entre empresas, prestadores e clientes. Esta correção exigirá, ainda assim, uma maior definição do padrão de competitividade proposto para o setor, que tem sido a base da ação das demais agências da indústria de serviços de utilidade pública.

0 arranjo organizacional de regulação da prestação de serviços de saúde pelo desenho de agência del egada não teve paral elo na experiência setorial da saúde brasileira, ainda que o processo de descentralização da prestação de saúde e da vigilância em saúde tenha dado ao M inistério da Saúde poderes quase legislativos, como identifica a literatura para outros contextos ${ }^{5}$. 0 desenho de um modelo regulatório que gere eficiência das empresas, responsabilidade social e qualidade na atenção à saúde constitui-se, de fato, em um desafio, pelo aprendizado que pode trazer para a gestão pública na saúde.

A orientação deum regimeregulatório define, em grandemedida, o queéaceitável para ainteração entre Estado e o setor privado. As preferências dos agentes estatais influenciam nas interpre- 
tações sobre as tendências do mercado, nas aplicações das lições de outros países e no modo que a nova regulação é colocada em prática ${ }^{1}$.

Os atores estatais têm escolhas autônomas, atuam a partir dessas preferências e geram resultados na ação regulatória que não refletem apenas os interesses privados. Em razão do forte poder de intervenção sobre o mercado de planos de saúde, o problema da delegação de poder à agência reguladora e da estabilidade das regras e normasinstituídas ao setor regulado assumeuma importância crucial para a credibilidade do regime regulatório e perspectivas futuras do setor.

A legitimidadeda regulação no campo da atenção à saúde traz, de fato, um problema teórico adicional, tendo em vista queas experiências bemsucedidas no setor são aquelas em que o gover- no regula as condições sistêmicas de financiamento e provisão de bens públicos e serviços de saúde $^{18}$. Os modelos de regulação sistêmicos privilegiam a decisão do governo na alocação e no uso dos recursos ${ }^{19}$. A experiência de regulação da "indústria de seguro de saúde" écaracterística do arranjo institucional do sistema de saúde dos Estados Unidos, embora a Europa venha se defrontando com o tema em função da presença dos planos de saúde voluntários em muitas economias nacionai $\varsigma^{20}$. 0 padrão de regulação pontual observado nos Estados Unidos tem ampliado a fragmentação, inibiu a universalização, não controlou a expansão dos gastos e nem a alocação ineficiente de recursos ${ }^{19,21}$. Este é certamente 0 desafio para o futuro do regime de regulação dos planos de saúde no Brasil ${ }^{22}$.

\section{Referências}

1. Vogel SK. Freer markets, more rules. Ithaca: Cornel University Press; 1996.

2. Lane JE. The public sector: concepts, models and approaches. London: Sage; 1993.

3. Majone G. Regulating Europe. London: Routledge; 1996.

4. Wilson JQ. Political organizations. New Jersey: Princeton; 1995.

5. Scott $C$. Privatization and regulatory regimes. In: Moran M, Rein M, Goodin RE, editors. The Oxford Handbook of Public Policy. Oxford: Oxford University Press; 2006. p. 651-668.

6. Armstrong M, Cowan S, Vickers J. Regulatory reform - economic analysis and British experience, Cambridge: MIT Press; 1995.

7. Nunes E. Reforma administrativa, reforma regulatória: nova face da relação Estado-economia no Brasil. Rio de Janeiro: UCAM; 1999.

8. Costa NR, Silva PLB, Ribeiro JM, M elo MAC. O desenho institucional da reforma regulatória. Revista de Administração Pública 2001: 35(2):193-228.

9. Agência Nacional de Saúde Suplementar. Cadernos de Informação da Saúde Suplementar. Rio de Janeiro: ANS; 2007

10. World Bank. Organização, Prestação e Financiamento da Saúde no Brasil. Washington, D.C.: World Bank; 1995.

11. Ayres I, Braithwaite J. Responsive regulation: transcending the deregulation debate. Oxford: Oxford University Press; 1992.

12. Souza MTCS. 0 modelo de agência reguladora e a ANS [dissertação]. Rio de Janeiro (RJ): EN SP/Fiocruz; 2003.

13. Araujo AM. A regulação do mercado de saúde suplementar no Brasil: barreiras à entrada eà saída de empre sas de plano e seguro de saúde de planos privados [dissertação]. Rio de Janeiro (RJ): ENSP/Fiocruz; 2003.
14. Rocha F. Prevenção estratégica à entrada. In: Kupfer $D, H$ asenclever $L$, organizadores. Economia industrial - fundamentos teóricos e práticas no Brasil. Rio de Janeiro: Campus; 2002. p. 239-263.

15. Stiglitz JE. Economics of the public sector. New York: W.W. Norton; 1999.

16. Baumol WJ, Blinder AS. Economics: principles and policy. Orlando: Harcourt Brace College Publishers; 1997.

17. Kupfer D, Hasenclever L. Barreiras estruturais à entrada in economia industrial - fundamentos teóricos e práticas no Brasil. Rio de Janeiro: Campus; 2002. p.109-128.

18. Dunlop DW, Martins J M. An international assessment of health care financing - lessons for developing countries. Washington, D.C.: World Bank; 1995.

19. H siao WC. A framework for assessing health financing strategies and the role of health insurance. In: Dunlop DW, Martins J M, editors. An international assessment of health care financing - lessons for developing countries. Washington, D.C.: World Bank; 1995. p. 15-30.

20. Mossialos E, Dixon A, Figueras J, Kutzin J. Funding health care: options for Europe, M aidenhead: Open University Press; 2002.

21. Feldstein P. Health policy issues a economic perspective. Chicago: Health Administration Press; 1999.

22. Costa NR, Castro AJW. O regime regulatório e estrutura do mercado de planos de assistência à saúde no Brasil. Regulação e Saúde 2003; 3:49-64.

Artigo apresentado em 09/07/2007

Aprovado em 20/08/2007

Versão final apresentada em 30/10/2007 